\title{
Incidence of influenza-like illness into a cohort of patients affected by chronic inflammatory rheumatism and treated with biological agents
}

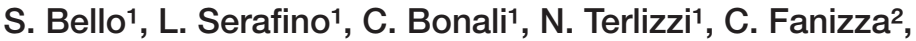 \\ C. Anecchino², G. Lapadula ${ }^{1}$ \\ 1 Unità Operativa di Reumatologia, Ospedale Policlinico, Bari, Italy; \\ ${ }^{2}$ Consorzio Mario Negri Sud, Santa Maria Imbaro (CH), Italy
}

\begin{abstract}
SUMMARY
This study aimed to evaluate the incidence of influenza-like illness (ILI), from October 2009 to May 2010, in a group of patients suffering from chronic inflammatory rheumatism and treated with biological therapies. At the end of 2009-2010 influenza season, 159 patients under biological therapies answered to a questionnaire distributed 8 months before and were deeply interviewed. The group included 69 men and 90 women (mean age 47.6); 49 suffering from rheumatoid arthritis, 61 with psoriatic arthritis, 32 with ankylosing spondylitis and 17 with other spondyloarthritis; 146 patients were treated with anti-TNF- $\alpha, 7$ with rituximab and 6 with abatacept; 128 patients assumed DMARDs and 72 patients assumed low dose of steroids. A case of ILI was identified by anamnestic findings and according to the case definitions commonly used in Europe.

$17 \%$ of the considered population reported at least one episode of ILI during the monitoring period; none of the patients during the acute influenza attack suffered particularly severe symptoms and no one was hospitalized due to complications. Despite the diversity among the considered subgroups, the statistical analysis did not show any significant difference when incidence of ILI was considered for different disease, different biological agent and different association therapy. None of the examined variables resulted statistically significant concerning the relative risk evaluation.

The incidence of ILI into a cohort of 159 patients treated with biological agents during the influenza season 2009-2010 resulted higher than the value reported in a wide sample of Italian population in the same period. However, the pandemic impact was not heavy among the studied patients, considering that no important complications or hospitalizations have been reported.
\end{abstract}

Key words: Influenza-like illness, A/H1N1 influenza, biological therapy, 2009-2010 influenza season.

Reumatismo, 2012; 64 (5): 299-306

\section{INTRODUCTION}

Datients affected by chronic inflammatory rheumatism are at greater risk of infection compared with the general population, because of the disease and its effects on the immune system, and the use of drugs that interfere with the immune system (1). Among these latter, mention must be made of steroids, synthetic disease modifying antirheumatic drugs (DMARDs) and biological DMARDs. The latter are increasingly used against rheumatism, and often in association with synthetic DMARDs and/or steroids. Great efficacy has been seen in the treatment of certain diseases, with ac- ceptable risk levels, but the greatest danger is the possibility that patients in therapy develop new infections or see latent infections breaking out.

Several studies exist in the literature on the reactivation of tuberculosis, hepatitis, and opportunistic infections in patients undergoing bio-technological therapy (2), whereas we found very few reports concerning the effect of influenza virus in patients treated with immunomodulatory drugs. The latter mostly affect anti-influenza vaccinations in patients being treated with biological drugs, and an increase in antibodies has been seen; there is an immunosufficient response to guarantee pro-
Corresponding author:

Dr. Sandro Bello

Via Ferrannini, 27/e - 70125 Bari, Italy

E-mail: s.bello1@virgilio.it 
tection, although it is often less than in the control group; vaccination does not seem to worsen the disease, and there do not appear to be serious side effects in these patients (3-5). Additionally, EULAR recommendations for the vaccination of patients with auto-immune inflammatory rheumatism suggest giving these patients the influenza vaccination (6).

Pneumonia is the most common serious complication of influenza, and is one of the greatest causes of death in patients with rheumatoid arthritis $(7,8)$. The influenza virus is one of the most frequent causes of Community Acquired Pneumonia (CAP, infection of the lungs that affect individuals who have not recently been hospitalized), accounting for up to $22 \%$ of the cases examined $(9,10)$. The mortality rate for influenza-related CAP was $4.4 \%$ in a recent, wide-ranging study in Germany (11). The incidence of bacterial or viral pneumonia, in a US study on 16,000 patients undergoing pharmacological treatment for rheumatoid arthritis and then monitored for 3.5 years showed 17 cases/1000 patients/ year. The same study also showed that treatment with prednisone and leflunomide increased the risk of pneumonia, whereas treatment with salazopirina, metotrexato, etenercept, adalimumab, and infliximab saw no increase in risk levels (12).

In late April 2009, the emergence of a new type of influenza virus was reported in Mexico and the US, known asA/H1N1v. The rapid spread of this virus forced the WHO to declare a state of full-scale pandemic in June 2009. Both countries increased their surveillance measures to contain and treat the influenza pandemic (13). In Italy, virus monitoring is carried out by the Italian WHO centre for influenza at the Medical Register, with the help of INFLUNET who actually collect data (14). INFLUNET is a front-line surveillance network, which collects clinical and virus information from all over Italy. The system is based on sentinel practitioners, general practitioners (GPs) and paediatricians, covering about $1.5-2 \%$ of the general population; they monitor the incidence of influenza-like illnesse (ILI), identify the spread of the disease, and col- lect information about the viruses in circulation, from week 42 to week 17 of the following year each influenza season $(15,16)$. With the help of mathematical models, showing that the vaccination of $40 \%$ of the Italian population was an appropriate measure to mitigate the pandemic, the Health Department decided to purchase 24 million doses of vaccine (MF59) and distributed them around the country; this was after identifying the highest-risk categories, those most in need of vaccination. When the period ended, only $4.2 \%$ of the target population was seen to have received the first dose of the vaccine $(871,277$ people) (13). During the monitoring period, INFLUNET collected and analysed 16,399 clinical samples, 6271 (38.2\%) of which were influenza virus infection positive. Type-A viruses were the most predominant $(99.2 \%)$, and Type-B viruses only accounted for $0.8 \%$. H1N1v was diagnosed in $96.4 \%$ of all cases (14).

Incidence of ILI in Italy during influenza season 2009/2010 was 97 cases per thousand people: $240 / 1000$ in under$15 \mathrm{~s}, 64 / 1000$ in the age range $15-64$, and 26/1000 among the over 65s. Approximately 1100 cases were sent to hospital with serious symptoms, 532 of which went into intensive care, 49 required ECMO (Extra-Corporeal Membrane Oxygenation), 166 were diagnosed with acute respiratory distress syndrome, and 166 had to be intubated. A total of 260 deaths due to influenza complications were reported; in $43 \%$ of hospitalized cases was identified the coexistence of a serious disease as a risk factor $(13,14)$.

In July 2009, the CROI (Collegio dei Reumatologi Ospedalieri Italiani) newspaperpublished advice on managing $\mathrm{A} / \mathrm{H} 1 \mathrm{~N} 1$ in rheumatic patients, in line with the suggestions given by the Société Française de Rheumatologie (17). In October 2009, the Italian Society of Rheumatology gave advice on the new $\mathrm{A} / \mathrm{H} 1 \mathrm{~N} 1$ virus to patients suffering from chronic inflammatory disease receiving treatment with immunomodulant drugs and therefore at greatest risk of viral contagion and complications like pneumonia (18). Since the vaccine for 
the pandemic strain was not available at the time, anti-pneumococcal vaccination was recommended alongside the seasonal influenza vaccine. It was decided that rheumatic patients receiving immunosuppressive drugs were to be given the $\mathrm{A} / \mathrm{H} 1 \mathrm{~N} 1$ vaccine as soon as it became available. In the event of ILI symptoms appearing, patients were told to report to their GPs, to suspend DMARD and biological treatment (but not the steroids) for approximately seven days, to take antiviral treatment if they were carrying some serious disease, and told to stay at home until their symptoms went away. Levels of panic rose as people watched the TV reports on the spread and seriousness of the pandemic, and this even affected out-patients receiving biological treatment at the Rheumatology Unit, Policlinico Hospital of Bari. To find a solution for all these problems, patients were given detailed, verbal information and a copy of the recommendations of the Italian Society of Rheumatology (18).

The aim of this study was to assess incidence of ILI in the period between October 2009 and May 2010, in a group of patients suffering from chronic inflammatory rheumatism, who accounted for $24.3 \%$ (159 out of 655) of all patients receiving biological drugs at the Rheumatology Unit, Policlinico Hospital of Bari.

\section{PATIENTS AND METHODS}

Towards the end of the 2009-2010 influenza season, 159 patients being treated with biological drugs filled in a questionnaire which had been handed out eight months beforehand with a series of recommendations for the patients receiving immunomodulatory drugs for the new influenza A/ $\mathrm{H} 1 \mathrm{~N} 1$, and then they were interviewed. A case of ILI was identified by anamnestic finding of acute respiratory affection with brief and sudden onset, with fever $\geq 38^{\circ}$, followed at least by one symptom among headache, generalized malaise, feeling of fever (sweating, chills), fatigue, accompanied with at least one respiratory symptom among cough, sore throat and nasal conges- tion. It was also required to the patient to indicate, the number of influenza episodes suffered, the month of onset and the severity of the symptoms. At the same time was requested if it was necessary to discontinue the biological therapy, to assume antibiotics and/or antiviral agents, if it was necessary the hospitalization and if the patient undergone the influenza H1N1 diagnostic test.

\section{Statistical analysis}

The incidence of ILI was reported as frequency and rate according to clinical and epidemiological features of patients; the statistical differences among subgroups was evaluated through the $\chi^{2}$-test or the Fisher's exact test for small samples, as categorical variables. The risk evaluation was obtained through the calculation of the relative risk (RR) and its statistical significance through the confidence interval (CI) and the $\mathrm{p}$ value.

\section{RESULTS}

The group included 69 males and 90 females, aged between 13 and 79 (average 47.6); 49 suffered from rheumatoid arthritis, 61 from psoriatic arthritis, 32 from ankylosing spondylitis, and 17 from other spondyloarthritis (undifferentiated spondyloarthritis, enteropathic arthritis, and reactive arthritis). One hundred forty-six were receiving anti-TNF treatment (51 infliximab, 42 adalimumab, 53 etanercept), 7 with rituximab, and 6 abatacept; 128 were under therapy with DMARDs (118 methotrexate, 7 ciclosporina, 1 leflunomide, 2 salazopirina), and 73 with low-dosage steroids. Thirtyfour had been vaccinated against the seasonal influenza (28 in the previous years), 4 had received antipneumococcal vaccination (4 in the previous years), and 12 had been vaccinated against A/H1N1 influenza (Tab. I). The $53.5 \%$ of patients also suffered from comorbidities, which required therapy in $91.8 \%$ of cases: $30.2 \%$ were suffering from cardiovascular diseases, $13.8 \%$ from gastro-intestinal complaints, $6.3 \%$ diabetes mellitus, 5\% from lung disease, and $2.5 \%$ nephropathy. 
Seventeen percent of all patients reported at least one episode of ILI during the period of observation (1-3; average 1.3), with $40.7 \%$ of all cases occurring in January. Incidence by disease showed $12.2 \%$ for rheumatoid arthritis, $16.5 \%$ for psoriatic arthritis, $25 \%$ for ankylosing spondylitis, and $17.5 \%$ for other spondyloarthritis. ILI rates in patients with comorbidities were $17.6 \%$ vs $19.3 \%$ for patients only suffering from rheumatism.

The obtained incidence for different age groups resulted respectively $21.4 \%$ from
0 to 30 years, $14.8 \%$ from 31 to 50 years and $18.8 \%$ over 50 years. The incidence in patients vaccinated against seasonal influenza was $26.5 \%$ vs $14.4 \%$ in notvaccinated patients. The incidence in patients vaccinated against $\mathrm{H} 1 \mathrm{~N} 1$ influenza resulted $25.0 \%$ vs $16.3 \%$ in not-vaccinated patients (Fig. 1C). The incidence considered for different biological agents resulted $13.7 \%$ for infliximab, $19 \%$ for adalimumab, $16.9 \%$ for etanercept, $28.5 \%$ for rituximab and $16.6 \%$ for abatacept. The incidence of ILI in the group of pa-

Table I - ILI incidence according to patient clinical and epidemiological characteristics.

\begin{tabular}{|c|c|c|c|c|}
\hline & Patients & ILI cases & Incidence (\%) & $P$ value \\
\hline Age & & & & 0.74 \\
\hline$\leq 30$ & 14 & 3 & 21.4 & \\
\hline $31-50$ & 81 & 12 & 14.8 & \\
\hline$>50$ & 64 & 12 & 18.8 & \\
\hline Gender & & & & 0.58 \\
\hline Female & 90 & 14 & 15.5 & \\
\hline Male & 69 & 13 & 18.8 & \\
\hline Disease & & & & 0.52 \\
\hline PSA & 61 & 10 & 16.5 & \\
\hline RA & 49 & 6 & 12.2 & \\
\hline AS & 32 & 8 & 25.0 & \\
\hline SPA & 17 & 3 & 17.5 & \\
\hline Biological drug & & & & 0.90 \\
\hline ETA & 53 & 9 & 16.9 & \\
\hline IFX & 51 & 7 & 13.7 & \\
\hline $\mathrm{ADA}$ & 42 & 8 & 19.0 & \\
\hline RIT & 7 & 2 & 28.5 & \\
\hline $\mathrm{ABA}$ & 6 & 1 & 16.6 & \\
\hline Therapy type & & & & 0.69 \\
\hline Bd only & 24 & 3 & 12.5 & \\
\hline $\mathrm{Bd}+\mathrm{Dm}+\mathrm{St}$ & 66 & 13 & 19.7 & \\
\hline $\mathrm{Bd}+\mathrm{Dm}$ & 62 & 9 & 14.5 & \\
\hline $\mathrm{Bd}+\mathrm{St}$ & 7 & 2 & 28.6 & \\
\hline Vaccinations & & & & 0.05 \\
\hline Yes & 41 & 11 & 26.8 & \\
\hline No & 118 & 16 & 13.5 & \\
\hline Seasonal influenza & & & & 0.09 \\
\hline Yes & 34 & 9 & 26.5 & \\
\hline No & 125 & 18 & 14.4 & \\
\hline Influenza A (H1N1) & & & & 0.44 \\
\hline Yes & 12 & 3 & 25.0 & \\
\hline No & 147 & 24 & 16.3 & \\
\hline
\end{tabular}

RA: rheumatoid arthritis; PSA: psoriatic arthritis; AS: ankylosing spondylitis; SPA: other spondyloarthritis; IFX: infliximab; ADA: adalimumab; ETA: etanercept; RIT: rituximab; ABA: abatacept; Bd: biological drug; Dm: DMARD; St: steroids. 
tients treated with only biological drug $(12.5 \%)$ was lower than that detected in the groups of patients using the biological therapy+DMARD (14.5\%), biological therapy+steroids (28.6\%) and biological therapy+DMARD+steroids (19.7\%; Tab. I). The statistical analysis did not show any significant difference, probably due

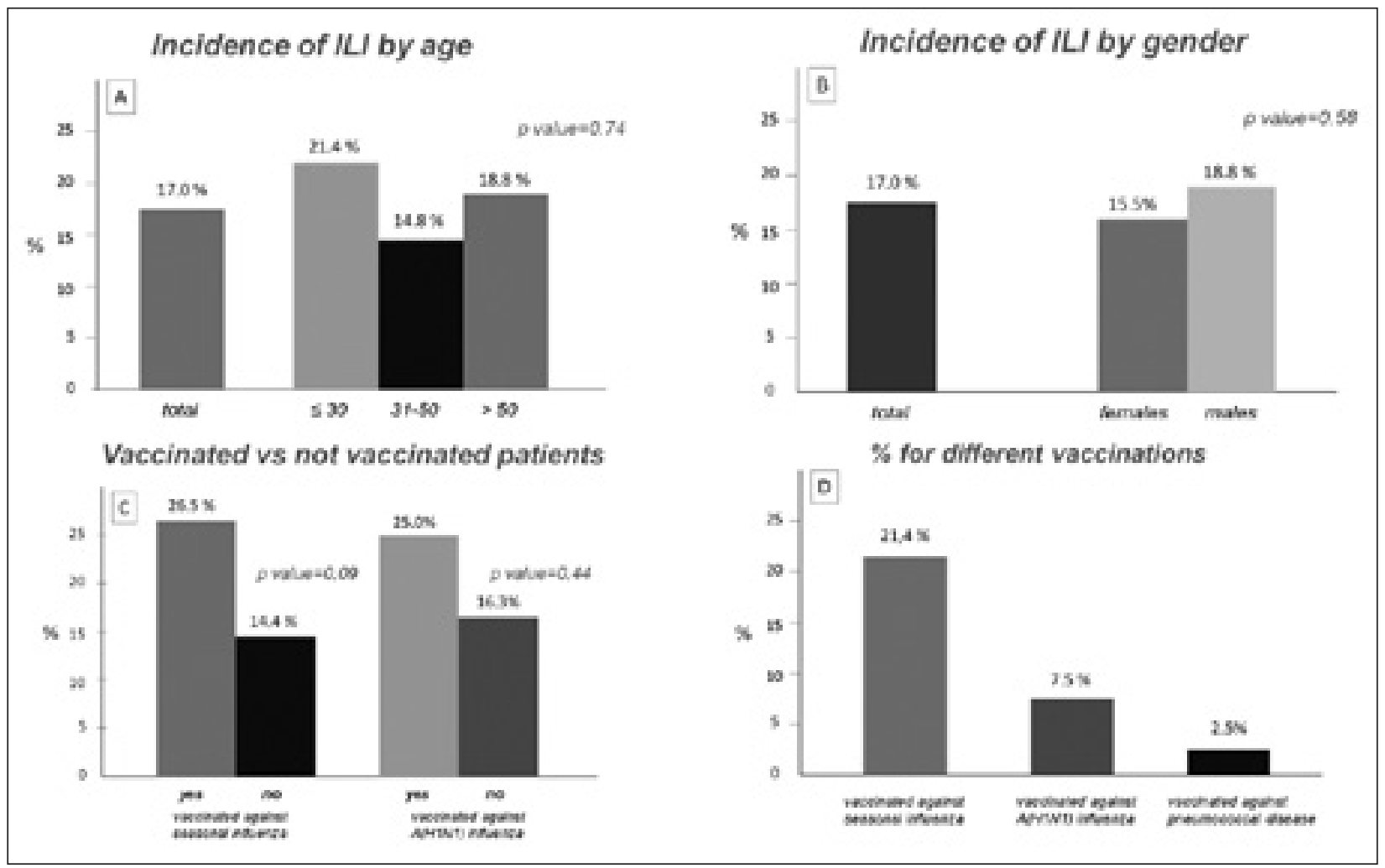

Figure 1 - Incidence of ILI within the specific population, according to age (A), gender (B), and vaccination type $(C)$; rate of patients vaccinated in the group monitored (D).

Table II - Quantitative assessment of risk factor and statistical significance.

\begin{tabular}{|l|l|l|l|}
\hline Variable & IRR $^{\star}$ & $95 \% \mathbf{C l}$ & p value \\
\hline Age & 0.996 & $0.967-1.027$ & 0.813 \\
\hline Gender & & & \\
\hline Male & 1.211 & $0.610-2.407$ & 0.585 \\
\hline Female & 1 & & \\
\hline Diseases & & & \\
\hline Rheumatoid arthritis & 0.641 & $0.276-1.489$ & 0.302 \\
\hline Spondyloarthritis & 1 & & \\
\hline Biological drug & & & \\
\hline Anti-TNF & 0.712 & $0.247-2.051$ & 0.530 \\
\hline Other than anti-TNF & 1 & & \\
\hline Therapy type & & & \\
\hline Associated biological & 1.422 & $0.465-4.354$ & 0.537 \\
\hline Only biological & 1 & & \\
\hline Vaccination (at least one of those considered) & & & \\
\hline Yes & 1.979 & $1.002-3.908$ & 0.049 \\
\hline No & 1 & & \\
\hline & & & \\
\hline
\end{tabular}


to the small dimension of the examined samples. None of the patients during the acute influenza attack suffered particularly severe symptoms and no one were hospitalized due to complications; $22.2 \%$ of the patients discontinued for few days the biological therapy, $51.8 \%$ assumed antibiotics and no one assumed antiviral therapies; none of the patients undergone the influenza H1N1 diagnostic test. None of the examined variables resulted statistically significant concerning the relative risk evaluation (Tab. II).

\section{DISCUSSION}

The incidence of ILI in a cohort of 159 patients under treatment with biological drugs during the 2009-2010 influenza period was $17 \%$ (Fig. 2A), decidedly higher than the figures seen with a larger sample taken in Italy (2\%) at the same time $(9.7 \%)$ $(13,14)$.

Considering the absence of hospital admissions and particularly serious symptoms, and the limited number of patients who changed therapy during ILI, the impact of the pandemic can certainly be considered as light among the sample considered by us; the rarity in the literature of reports of the effect of influenza viruses on patients being treated with biotechnological drugs during the pandemic appears in line with this consideration $(20,21)$. Discussion in the literature of proof in laboratory animals of the responsibility of TNF- $\alpha$ as a mediator for pulmonary inflammation during viral pneumonia, and the positive effects it has the treatment with anti-TNF on symptoms and anatomopathological lesions in the same animals seems important $(22,23)$. Small percentage differences in favour of males and young people (Fig. 1A, B) were

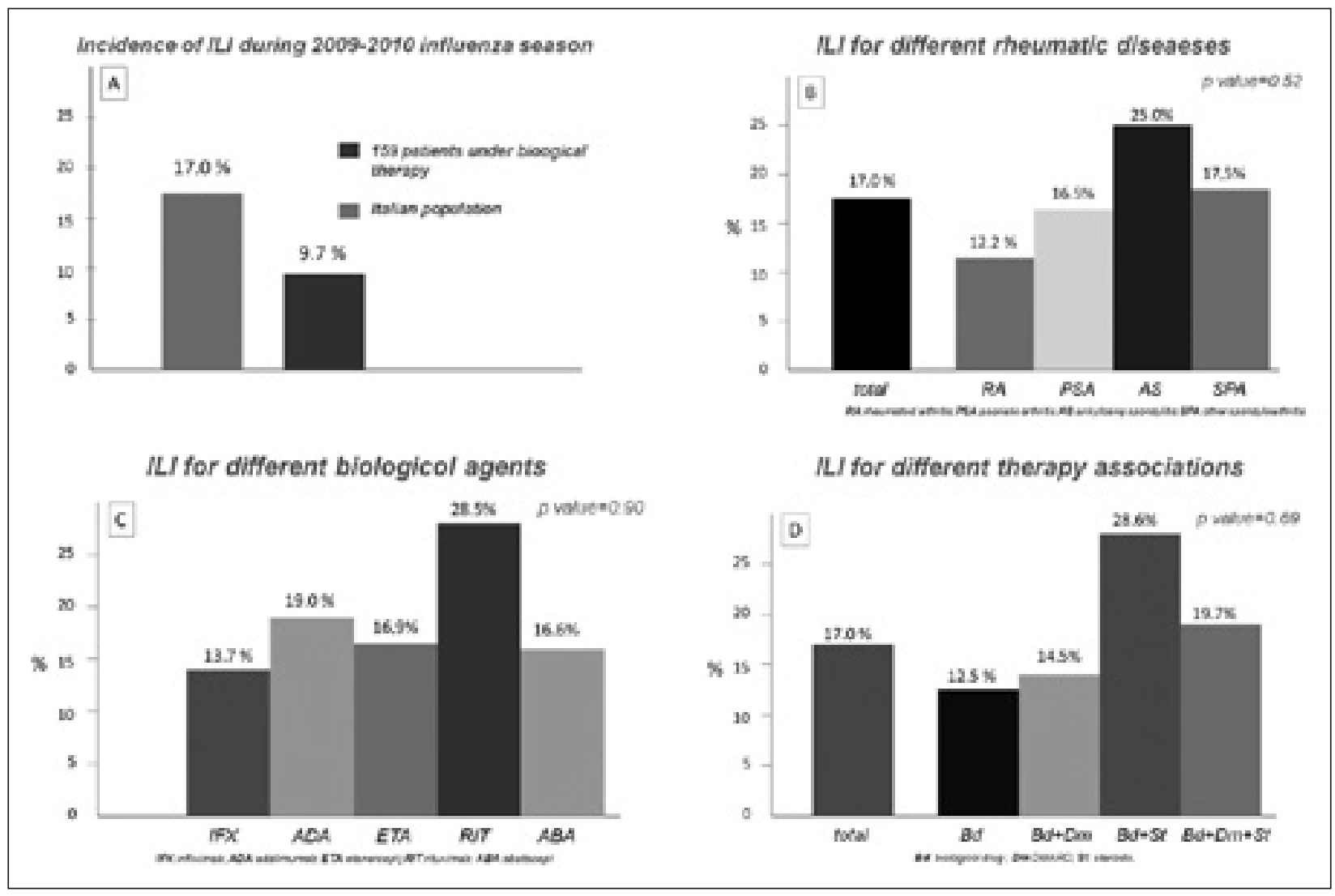

Figure 2 - Incidence of ILI in the considered population (A), distributed by pathology (B), biological drug $(C)$, and associated therapy (D). 
not statistically significant ( $\mathrm{p}$ value 0.558 and 0.74 ). Distribution by disease was not statistically significant either ( $\mathrm{p}$ value 0.52 ), whereas a greater incidence was seen among patients affected by ankylosing spondylitis, and lesser incidence in patients with rheumatoid arthritis (Fig. 2B). ILI was more frequent in patients being treated with rituximab then other biologicals (Fig. 2C), and less frequent among patients receiving only biologicals than those who took it with DMARDs or steroids, or all three together (Fig. 2D); however, even the differences between these groups were not statistically significant ( $\mathrm{p}$ value 0.90 and 0.59).

From the quantitative risk assessment, the male gender compared with female (IRR:1.211) and the combination therapy compared with only biological therapy (IRR:1.422) resulted as risk factors; protective factors were the diagnosis of rheumatoid arthritis rather than spondyloarthritis (IRR:0.641) and therapies with anti-TNF over other biologicals (IRR:0.712). However, it must be stressed that none of the variables considered were statistically significant. To find possible reasons for the greater incidence of ILI among patients with spondyloarthritis than those with rheumatoid arthritis, two groups were compared: patients with rheumatoid arthritis had a higher average age (52.5 vs 45.4), a greater prevalence of comorbidities $(63.3 \%$ vs 5.5), they were more likely to take DMARDs (85.7\% vs $78.2 \%)$ and steroids (79.6\% vs $30.9 \%$ ), but most frequently took the receptor $(42.8 \%$ vs $29.1 \%)$ rather than the anti-TNF monoclonal antibody $(30.6 \%$ vs $70.9 \%$ ); patients with rheumatoid arthritis and spondyloarthritis with at least one episode of ILI were more likely to take etanercept (57.1 vs 28.6) than infliximab and adalimumab (0\% vs $71.4 \%)$; it is therefore reasonable to suppose that in patients with rheumatoid arthritis receptor-therapy rather than antibody-therapy may explain the lower incidence of ILI than among patients suffering from spondyloarthritis. In spite of the feelings of fear generated by the spread of the pandemic, and notwithstanding the information and advice we gave, only $21.4 \%$ of patients were found to have been vaccinated against seasonal influenza, and even fewer against AH1N1 influenza $(7.5 \%)$ or pneumococcus $(2.5 \%)$ (Fig. 1D). In 41 patients who said they had received at least one of these vaccinations, incidence of ILI was $26.8 \%$, against the $13.5 \%$ among unvaccinated patients, and the difference was at the limit of statistical significance ( $p$ value 0.05 ); risk assessment also showed that in vaccinated patients the risk of ILI was twice what it was among unvaccinated patients (IRR:1.979), and this variable is at the limit of statistical significance (95\% CI:1.002-3.908 and p value 0.049 ). It was difficult to find a reasonable explanation for this result, and the information from interviews was not completely significative to us, missing of data concerning the functional compromising, the ability to lead a social life, and the type of employment (for example, if the patient worked in situations with a high risk of contagion), the type of family, and incidence of ILI among other family members. We also assessed time differences between giving the vaccine and the onset of ILI among patients vaccinated against seasonal influenza and/or A/H1N1who reported at least one episode of ILI; barely $18.2 \%$ reported the onset of ILI during November and December, when the vaccine was given; considering, therefore, that vaccine reaction usually begins 6-12 hours after inoculation, and that more than $80 \%$ of patients developed ILI long after taking the vaccine, it appears likely that vaccine reaction did not cause a greater incidence of ILI among vaccinated patients.

In conclusion, we saw that incidence of ILI among patients receiving biotechnological drugs during the 2009-2010 influenza season was greater than in the general population, but that the effects of the pandemic on the group of patients under study were very mild and with no truly serious consequences; nor had many patients been vaccinated, although they had been encouraged to do so. We found no evidence of differences when incidence of ILI was considered for different disease, different biological agent and different association therapy. 


\section{REFERENCES}

1. Doran MF, Crowson CS, Pond GR, O'Fallon WM, Gabriel SE. Frequency of infection in patients with rheumatoid arthritis compared with controls: a population-based study. Arthritis Rheum 2002; 46: 2287-93.

2. Furst DE, Keystone EC, Braun J, Breedveld FC, Burmester GR, De Benedetti F, et al. Updated consensus statement on biological agents for the treatment of rheumatic diseases, 2010. Ann Rheum Dis 2011; 70: i2-36.

3. Gelinck LB, van der Bijl AE, Beyer WE, Visser LG, Huizinga TW, van Hogezand RA, et al.The effect of anti-tumour necrosis factor alpha treatment on the antibody response to influenza vaccination. Ann Rheum Dis 2008; 67: 713-6.

4. Kapetanovic MC, Saxine T, Nelsson JA, Geborek P. Influenza vaccination as model for testing immune modulation induced by antiTNF and methotrexate therapy in rheumatoid arthritis patients. Rheumatology 2007; 46: 608-11.

5. Elkayam O, Bashkin A, Mandelboim M, Litinsky I, Comaheshter D, Levartovsky D, et al. The effect of infliximab and timing of vaccination on the humoral response to influenza vaccination in patients with rheumatoid arthritis and ankylosing spondylitis. Semin Arthritis Rheum 2010; 39: 442-7.

6. Van Assen s, Agmon-Levin n, Elkayam O, Cervera R, Doran MF, Dougados M, et al. Eular recommendations for vaccination in adult patients with autoimmune inflammatory rheumatic diseases. Ann Rheum Dis 2011; 70 : 414-22.

7. Wolfe F, Mitchell DM, Sibley JT, Fries JF, Bloch DA, Williams CA, et al. The mortality of rheumatoid arthritis. Arthritis Rheum 1994; 37: 481-94.

8. Hara K, Yahara K, Gotoh K, Nakazono Y, Kashiwagi T, Imamura Y, et al. Clinical study concerning the relationship between community-acquired pneumonia and viral infection in northern Thailand. Intern Med 2011; 50: 9918.

9. Shibli F, Chazan B, Nitzan O, Flatau E, Edelstein H, Blondheim O, et al. Etiology of community-acquired pneumonia in hospitalized patients in northern Israel. Isr Med Assoc J 2010; 12: 477-82.

10. Mermond S, Berlioz-Arthaud A, Estivals M, Baumann F, Levenes H, Martin PM. Aetiology of community-acquired pneumonia in hospitalized adult patients in New Caledonia. Trop Med Int Health 2010; 15: 1517-24.

11. von Baum H, Schweiger B, Welte T, Marre R, Suttorp N, Pletz MW, et al. How deadly is seasonal influenza-associated pneumonia? The
German Competence Network for Community-Acquired Pneumonia. Eur Respir J 2011; 37: 1151-7.

12. Wolfe F, Caplan L, Michaud K. Treatment for rheumatoid arthritis and the risk of hospitalization for pneumonia: associations with prednisone, disease-modifying antirheumatic drugs, and anti-tumor necrosis factor therapy. Arthritis Rheum 2006; 54: 628-34.

13. Rizzo C, Rota MC, Bella A, Giannitelli S, De Santis S, Nacca G, et al. Response to the 2009 influenza $\mathrm{A}(\mathrm{H} 1 \mathrm{~N} 1)$ pandemic in Italy. Euro Surveill 2010; 15: pii=19744. Disponibile online: http://www.eurosurveillance.org/ViewArticle.aspx?ArticleId=19744

14. Ministero della Salute. Circolare DGPREV0034511-P- 29- 2010 "Prevenzione e controllo dell'influenza: raccomandazioni per la stagione 2010-2011. Disponibile online: http://urp.regione.abruzzo.it/2010

15. InfluNet, Rete Italiana Sorveglianza Influenza. Stagione influenzale 2009-2010: sorveglianza epidemiologica. Disponibile online: http://www.iss.it/flu/

16. InfluNet, Rete Italiana Sorveglianza Influenza. Protocollo operativo stagione influenzale 2010-2011. Disponibile online: http://www. iss.it/flu/

17. Il Giornale del CROI. Gestione del rischio di influenza H1N1 nei malati reumatici. Disponibile online: http://www.ilgiornaledelcroi.it

18. Società Italiana di Reumatologia. Consigli per i pazienti affetti da malattie reumatiche infiammatorie croniche in trattamento con farmaci immunosoppressori e biologici. Ottobre 2009. Disponibile online: http://www.reumatologia.it/cmsx.asp?IDPg=114

19. Aguilera JF, Paget WJ, Mosnier A, Heijnen ML, el al. Heterogeneous case definitions used for the surveillance of influenza in Europe. Eur J Epidemiol 2003; 18: 751-4.

20. Serrato VA, Azevedo VF, Sabatoski V, Gonçalves BP, Machado DM. Influenza $\mathrm{H} 1 \mathrm{~N} 1$ infection in a patient with psoriatic arthritis in treatment with Adalimumab: a case report. Clin Rheumatol 2010 Mar 5. [Epub ahead of print].

21. Kling MC, Larian AA, Scordi-Bello I, Emer J, Lebwohl MG. Fatal influenza A(H1N1) respiratory tract infection in a patient having psoriasis treated with infliximab. Arch Dermatol 2010; 146: 651-4.

22. Peper RL, Van Campen H. Tumor necrosis factor as a mediator of inflammation in influenza A viral pneumonia. Microb Pathog 1995; 19:175-83.

23. Hussell T, Pennycook A, Openshaw PJM. Inhibition of tumor necrosis factor reduces the severity of virus-specific lung immunopathology Eur J Immunol 2001; 31: 2566-73. 